diagnosed hypercalciuria on the results of testing a single urine collection. We believe it is important to record persistent hypercalciuria by testing repeated urine collections, as a single collection may be misleading.

The fact that two of our five hypercalciuric patients (both of whom had had episodes of gross haematuria) went on to develop calculi suggests that such patients should be treated. As idiopathic hypercalciuria is a lifelong, usually asymptomatic condition such treatment should probably be limited to recommending a diet low in calcium and ensuring that even patients who have never shown any evidence of stones in the renal tract should drink enough fluid.

\section{References}

1 Roy S III, Stapleton FB, Noe HN, Jerkins, G. Hematuria preceding renal calculus formation in children with hypercalciuria. J Pediatr 1981;99:712-5.

2 Kalia A, Travis LB, Brouhard BH. The association of idiopathic hypercalciuria and asymptomatic gross hematuria in children. J Pediatr 1981;99:716-9.

${ }^{3}$ Moore ES. Hypercalciuria in children. In: Berlyne GM, ed. Contributions to nephrology. New York: Karger, 1981:20-32.

${ }^{4}$ Hymes LC, Warshaw BC. Idiopathic hypercalciuria. Renal and absorptive subtypes in children. Am J Dis Child 1984;138: 176-80.

${ }^{5}$ Stapleton FB, Roy S III, Noe HN, Jerkins G. Hypercalciuria in children with hematuria. $N$ Engl J Med 1984;310:1345-8.

Correspondence to Dr H Stark, Paediatric Nephrology Unit, Beilinson Medical Centre, Petah Tiqva, 49100, Isreal.

Accepted 27 July 1987

\title{
Pulmonary interstitial emphysema: selective bronchial occlusion with a Swan-Ganz catheter
}

\author{
S LEWIS, E PELAUSA, C OJAH, AND B PAES
}

Division of Neonatology, Department of Paediatrics, McMaster University Health Sciences Centre, Chedoke-McMaster Hospital, Hamilton, Canada

SUMMARY A 26 week preterm infant ventilated for hyaline membrane disease developed severe pulmonary interstitial emphysema with extensive right sided bullous formation, mediastinal shift, and subsequent left sided atelectasis. A paediatric SwanGanz catheter was used for selective bronchial occlusion with dramatic improvement in the infant's clinical condition and radiographic findings.

Pulmonary interstitial emphysema (PIE) occurs as a complication of mechanical ventilation in infants with underlying hyaline membrane disease. The use of high peak ventilatory pressures with resultant barotrauma leads to extrapulmonary effusions of air along peribronchovascular, pleural, and interlobular passages from ruptured alveoli. ${ }^{1}$ The morbidity from the presence of such interstitial gaseous blebs stems largely from hypoxia secondary to a ventilation/perfusion imbalance in an already compromised infant. Accumulation of unilateral interstitial air may also result in bullous air pockets with eventual mediastinal shift and compression of the contralateral lung.

We report our experience with selective bronchial occlusion of the right mainstem bronchus with a Swan-Ganz catheter in a preterm infant with life threatening complications of PIE.

\section{Case report}

A girl weighing $760 \mathrm{~g}$ was born at 26 weeks' gestation by a vaginal breech delivery with an Apgar score of 5 and 6 at one and five minutes, respectively. The baby required mechanical ventilation almost immediately for moderately severe hyaline membrane disease (inspiratory pressures $14 / 3 \mathrm{~cm}$ $\mathrm{H}_{2} \mathrm{O}$; fractional inspiratory oxygen $\left.\left(\mathrm{FiO}_{2}\right) 1 \cdot 0\right)$. The initial chest radiograph taken five hours after birth showed early signs of bilateral PIE. At 12 hours of age a right pneumothorax occurred and was drained. Further deterioration in oxygenation necessitated increased ventilation (pressures $22 / 2 \mathrm{~cm}$ $\mathrm{H}_{2} \mathrm{O} ; \mathrm{FiO}_{2} 1 \cdot 0$ ). Ventilator support remained unchanged until day 16 , when radiographs indicated a worsening PIE that was associated with further hypoxaemia. Stabilisation proved difficult with recurrence of a right pneumothorax after increasing ventilatory pressures to $37 / 2 \mathrm{~cm} \mathrm{H}_{2} \mathrm{O} ; \mathrm{FiO}_{2} 0 \cdot 8$. Despite dependent positioning of the right emphysematous lung and carefully monitored ventilation, the infant continued to deteriorate.

On day 18 selective intubation of the left mainstem bronchus under fluoroscopy was unsuccessful. The radiographic findings (fig 1) showed large cystic lucencies with hyperaeration and a persistent herniation of the right lung across the midline with mediastinal displacement to the left. At this time the 


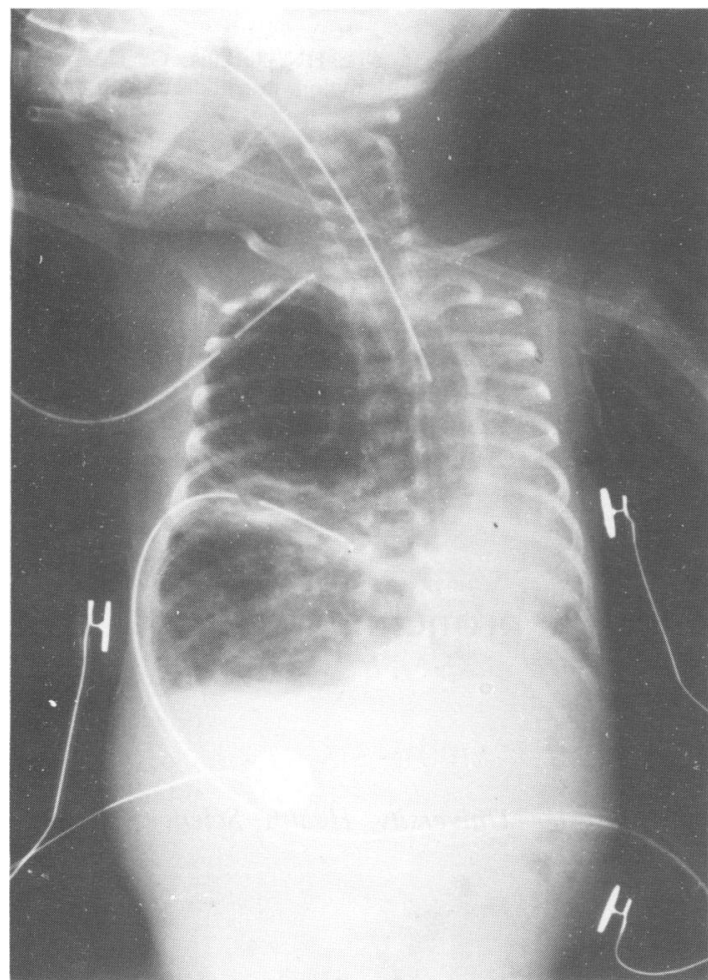

Fig 1 Large cystic lucencies of the right lung with hyperaeration and mediastinal shift to the left side. Two pneumothorax chest drains are shown on the right.

infant developed acute renal failure with intermittent hypotension concurrent with worsening arterial oxygen desaturation $\left(\mathrm{pH} 7 \cdot 17, \mathrm{PCO}_{2}\right.$ $10.4 \mathrm{kPa}, \mathrm{PO}_{2} 5.7 \mathrm{kPa}$, bicarbonate $28 \mathrm{mmol} / \mathrm{l}$ ). A decision was made to reattempt collapse of the right lung. This was easily achieved with a SwanGanz model 93-117-5 French double-lumen paediatric-flow directed monitoring catheter which was inserted into the right mainstem bronchus with balloon inflation to $0.8 \mathrm{~mm}$ diameter. The infant was then intubated with a No 2.5 endotracheal tube that was appropriately positioned above the level of the carina. The procedure was well tolerated and resulted in rapid reduction in inspiratory pressures and improvements in blood pressure, peripheral circulation, and oxygenation $\left(\mathrm{pH} 7.39, \mathrm{PCO}_{2}\right.$ $7 \cdot 1 \mathrm{kPa}, \mathrm{PO}_{2} 7.6 \mathrm{kPa}$, bicarbonate $\left.32 \mathrm{mmol} / \mathrm{l}\right)$. A chest film three hours later showed atelectasis of the middle and lower lobes of the right lung (fig 2) with a shift of the mediastinum to the midline and re-expansion of the left lung. The Swan-Ganz catheter was deflated intermittently for five minutes

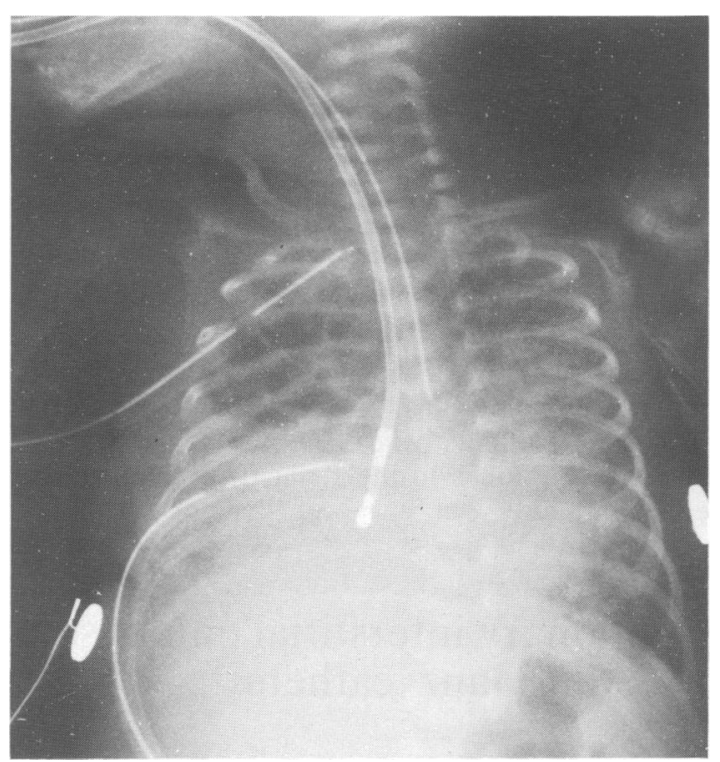

Fig 2 Partial atelectasis of the right lung with Swan-Ganz catheter in place.

every hour, to help minimise bronchial wall pressure necrosis. Forty eight hours later the left lung developed progressive radiological changes of PIE. The Swan-Ganz catheter was deflated for 12 hours and left in situ and then partially reinflated for a further 12 hours before being removed. Gradual reaeration of the right lung occurred with subsequent bilateral reabsorption of all the PIE. The infant was extubated at 9 weeks of age and has evidence of minimal bronchopulmonary dysplasia.

\section{Discussion}

Selective bronchial occlusion has been reported as a successful alternative in the treatment of localised PIE. ${ }^{2-4}$ The devices previously used to treat the diseased lung were not without procedural hazard. Mathew and Thach accomplished occlusion of the right mainstem bronchus with an umbilical catheter adapted with a handmade oesophageal pressure balloon, ${ }^{2}$ while DeWitte et al used a modified endotracheal tube with an occluded distal end. ${ }^{3}$ Auerbach et al used operative intervention for the insertion of a Fogarty balloon catheter at bronchoscopy in the management of localised cystic PIE. ${ }^{4}$ We chose a Swan-Ganz catheter because it is a safe and reproducible piece of equipment that can be easily inserted without large scale instrumentation that may further compromise the premature infant with PIE. The advantages of our procedure are that: 
(1) It is accomplished easily and quickly without fluoroscopy. (2) It comprises simple laryngoscopy with subsequent reintubation of the infant with a $0.5 \mathrm{~mm}$ smaller endotracheal tube to permit adjacent placement with the Swan-Ganz catheter. (3) A successful response is seen within half an hour of the procedure with ongoing improvement in the radiological findings. (4) The catheter is radiolucent and clearly marked in $5 \mathrm{~cm}$ increments with a sliding gate valve that prevents inadvertent deflation of the balloon. (5) Using a syringe, precise quantitation of the degree of balloon inflation is possible, and although location of the balloon is known $(0.9 \mathrm{~cm}$ from the catheter tip) its exact position can be determined by insufflating the balloon with dilute contrast fluid. Pulmonary interstitial emphysema should be managed aggressively in the first instance by non-invasive methods. Selective bronchial occlusion utilising a Swan-Ganz catheter provides a successful alternative measure in severe disease unresponsive to standard treatment.

References
1 Plenat F, Vert P, Didier F, Andre M. Pulmonary interstitial
emphysema. Clinics in Perinatology 1978;5:351-7.
2 Mathew OP, Thach BT. Selective bronchial obstruction for
treatment of bullous interstitial emphysema. J Pediatr 1980;96:
$475-7$.
3 DeWitte DB, Batton DG, Prudent L, Maisels J. Endotracheal
tube modification for therapy of right-sided pulmonary inter-
stitial emphysema. Clin Pediatr (Phila) 1986;25:626-8.
4 Auerbach DA, Blackmon LR, Filston HC, Merten DF,
Kirks DR. Localized pulmonary interstitial emphysema: treat-
ment by bronchial occlusion. American Journal of Perinatology
1983;1:52-7.

Correspondence and requests for reprints to Dr BA Paes, Department of Pediatrics (Neonatal Division), McMaster University Medical Centre, 1200 Main Street West, Hamilton, Ontario, Canada L8N 3 Z5.

Accepted 22 October 1987

\title{
Effect of tilting on oxygenation in newborn infants
}

\section{THORESEN, ${ }^{*}$ F COWAN,${ }^{*} \dagger$ AND A WHITELAW $\dagger$}

\begin{abstract}
${ }^{*}$ Department of Neonatology, Ullevaal Hospital, Oslo, Norway, and †Department of Paediatrics and Neonatal Medicine, Hammersmith Hospital, London
\end{abstract}

SUMmarY Transcutaneous (tc) $\mathrm{PO}_{2}$ in newborn infants increased on head up tilting (median increase $0.5 \mathrm{kPa}$ at term, $1.0 \mathrm{kPa}$ preterm). Head down tilting was associated with an equivalent fall in $t c \mathrm{PO}_{2}$. There was no change in tcPCO${ }_{2}$. Tilting of infants mechanically ventilated for respiratory distress syndrome or surgery produced no consistent change in $\mathrm{PO}_{2}$.

Newborn infants are often nursed on a head up tilt. This study investigated whether a head up or head down tilt produced a change in $\mathrm{PO}_{2}$ and $\mathrm{PCO}_{2}$ in healthy prone newborns and in those with respiratory problems.

\section{Patients and methods}

Seventeen healthy term infants and seventeen healthy preterm infants (mean birth weight $1300 \mathrm{~g}$ ) were studied at the Department of Neonatology, Ullevaal Hospital, Oslo. Each term infant lay prone and at least five tilts were performed. Each position: horizontal, 30 degrees head up, and 30 degrees head down, was held for five minutes before the next tilt. The term infants were studied on day one and day five in active and in quiet sleep. The preterm infants were studied on one day only and tilted 20 degrees head up in their incubators. Transcutaneous $\mathrm{PO}_{2}$ and $\mathrm{PCO}_{2}$ were measured in the interscapular region. Values were recorded every 30 seconds. Tilts associated with any body movement or change in sleep state were not included.

To investigate the possibility that $\mathrm{tcPO}_{2}$ might be influenced by changes in skin circulation from hydrostatic pressure or reflex vasoconstriction due to a baroreceptor response we measured $\mathrm{tcPO}_{2}$ from two electrodes, one in the intrascapular region and one on the buttock in five infants. $\mathrm{TcPO}_{2}$ values from both sites followed each other exactly (fig 1) thus ruling out a gravitational effect on local skin perfusion.

Further studies of $\mathrm{PO}_{2}$ and head up tilting were carried out in 10 infants receiving intensive care at Hammersmith Hospital, London. Seven of these infants had an umbilical artery catheter with an oxygen electrode at the tip in the descending aorta. The remaining three infants were studied using a transcutaneous $\mathrm{PO}_{2}$ system.

\section{Results}

Fig 1 shows a typical response with $\mathrm{PO}_{2}$ rising and 